\title{
MONTES DE PIEDAD ECLESIÁSTICOS Y PARTICULARES (S. XVIII-XIX): USOS MONETARIOS
}

\author{
POR \\ María Teresa MuÑoz Serrulla \\ Departamento de Ciencias y Técnicas Historiográficas y Arqueología, \\ Universidad Complutense, Madrid
}

\section{RESUMEN}

Los Montes de Piedad, instituciones benéfico-crediticias, surgen en Italia (S. XV) a iniciativa de predicadores franciscanos, con el objetivo de proporcionar préstamos sobre garantías prendarias a un interés más bajo que el exigido por los prestamistas. Este tipo de institución se propaga enseguida por toda la geografía italiana, traspasando sus fronteras llegará a otras zonas europeas, entre ellas a la Península Ibérica. En el seno de la monarquía hispana en los inicios del siglo XVIII tiene lugar la fundación del Monte de Piedad de Madrid, obra del Padre Piquer que será heredero del espíritu y objetivos de los primitivos Montes italianos incluirá algunas novedades fruto de la devoción de su fundador y de las características propias de la época. Este Monte se constituye a su vez en modelo de otras instituciones similares tanto en la península como en los virreinatos americanos. Con el paso del tiempo, se producen una serie de fundaciones que coinciden en la denominación (todas llevarán por nombre Monte de Piedad), pero con importantes diferencias en sus constituciones y fines. Estas fundaciones surgen tanto en ámbito eclesiástico, como secular. El análisis de alguna de estas instituciones es el objetivo del presente estudio, diferenciando fundaciones eclesiásticas y seculares (en estas últimas se distinguen las fundadas por miembros de la nobleza). Partiendo de los textos fundacionales se analizan los objetivos particulares o generales, su espíritu benéfico, y diferentes aspectos relacionados con su puesta en marcha, pleitos, utilización para fines diferentes de los señalados en su fundación, etc.

Palabras ClaVE: Montes de Piedad, Moneda, Crédito, Francisco Piquer. 


\title{
ECCLESIASTICAL AND PARTICULAR MOUNTS OF MERCY (MONTES DE PIEDAD) (S. XVIII-XIX): MONETARY USES
}

\begin{abstract}
Montes de Piedad (Mounts of Mercy), beneficial-credit institutions, arise in Italy (S. XV) to initiative of Franciscans preachers, with the objective to provide loans on pignoratious guarantees to an interest lower than the demanded by the moneylenders. This type of institution propagates immediately by all Italian geography, and going beyond its borders will arrive at other European zones, among them to the Iberian Peninsula. Within the Hispanic monarchy in the beginnings of century XVIII the foundation of Monte de Piedad of Madrid takes place, by Piquer Father who will be inheriting of the spirit and objectives of primitive Italian predecessors and will include some new features as a result of the devotion of their founder and the particularities of that time. This Monte will serve as a model for other similar institutions as much in the peninsula as in the American virreinatos. With time, a series of new foundations will take place, bearing the same denomination (all will take by name Monte de Piedad), but with important differences in their constitutions and aims. These foundations arise as much in ecclesiastical as secular scope. The analysis of some of these institutions is the objective of the present study, differentiating ecclesiastical and secular foundations (in these last ones a further difference is made for the ones founded by members of the nobility). Starting off from original texts, the particular or general objectives and their beneficial aims are analyzed and different aspects related to their start up, lawsuits, use for aims different from the indicated ones in their foundation, etc.
\end{abstract}

KEY WORDS: Mounts of Mercy (Montes de Piedad), Coin, Credit, Francisco Piquer.

Recibido/Received 17-03-2008

Aceptado/Accepted 03-06-2008

La historia de los Montes de Piedad se inicia en Italia durante el siglo XV, fruto de la iniciativa de los franciscanos y como medio para combatir la usura. Su implantación en la Península italiana es inmediata, fundándose Montes por toda su geografía.

Pretendían estas instituciones proporcionar una alternativa a los préstamos que, con elevados intereses facilitaban los usureros. Se instituían los Montes con un capital inicial que generalmente era depositado por personajes acaudalados de las ciudades, el propio gobierno de éstas e incluso en algunos casos, el producto de colectas populares organizadas con tal fin.

Hubo dos tipos de Montes. Los de las ciudades, denominados Montes de Piedad, concedían préstamos en metálico sobre prendas. Los de las zonas rurales, los Montes de Piedad Frumentarios, prestaban grano

En España, contamos con multitud de ejemplos de Montes, sin embargo no sería hasta el siglo XVIII cuando una de estas instituciones lograra perpetuarse.

Hispania Sacra, LXI

124, julio-diciembre 2009, 571-586, ISSN: 0018-215-X 
Es el caso del Monte de Piedad de Madrid. La intensa labor de su fundador, el Padre Francisco Piquer para afianzarlo económica e institucionalmente, se vio reflejada en las constituciones que le regirían. Gracias a esta labor las noticias de esta fundación, su actividad, objetivos y resultados, llegaron a otras ciudades en la Península y en los Virreinatos.

Estas noticias que, si bien en un principio se extendían intencionadamente para obtener apoyos económicos, se convertirían en la promoción de una obra imitada y serviría como modelo para posteriores Montes.

No fue éste el único Monte de Piedad y tampoco el primero. Podemos constatar, documentalmente, que existieron otras fundaciones similares, unas, la mayoría, con el mismo objetivo de los Montes de Piedad Frumentarios, que en España se denominaron pósitos, alhóndigas, etc., otras se llamaron Monte de Piedad, pero no con los mismos fines con los que originariamente se idearon. Algunos ejemplos de Montes son los que trataremos aquí, sus fundaciones, objetivos y desarrollo.

\section{MonTES DE PIEDAD EN EL ÁMBITO ECLESIÁSTICO}

Por medio de las dos fundaciones que estudiamos a continuación, veremos la institución de dos Montes con fines particulares claramente definidos en sus estatutos. Coinciden en son fundación de dos monasterios de la orden de San Bernardo en Galicia. Similares en sus fines y en su fecha de creación, puede pensarse en una solución común, adoptada por la orden para aliviar las dificultades económicas de diferentes monasterios en estas fechas

Monte de Piedad del Monasterio de Nuestra Señora de Acebeiro, Pontevedra, $1745^{1}$

La comunidad decide instituir un Monte de Piedad en 1745, tras reunirse para tratar sobre el gobierno temporal del Monasterio y sobre sus rentas. Estudiadas diferentes propuestas encaminadas a establecer medios para que las rentas se mantengan y aumenten, deciden crear un depósito al que denominan Monte de Piedad.

Su capital se determina en sus estatutos: El Padre Presidente debía depositar todos los años 50 ferrados $^{2}$ de centeno hasta completar la suma de 2.000 duca-

\footnotetext{
${ }^{1}$ AHN, Clero, L. 9919. Libro de depósito o Monte de Piedad de este Monasterio de Nuestra Señora de Acebeiro establecido en el año 1745, Pontevedra.

2 Unidad de medida utilizada en Galicia, su valor se estima entre 3 y 4 fanegas, aunque las equivalencias varían dependiendo de las zonas.
} 
dos de los que siempre deberán conservarse 1.000 en grano. Una vez alcanzada dicha cantidad se debía seguir haciendo estos depósitos anuales. Este capital servía a los Padres Presidentes en aquellos casos que necesitados de dinero para la manutención de esta Comunidad y «precisados por esto a vender los frutos a precios infimos y despreziables no los bendan y se prevalgan de el dinero de este particular deposito» ${ }^{3}$.

El Padre Cura más anciano desempeñaba el cargo de Depositario y los dos monjes más ancianos el de Contadores. La comunidad debía tomar cuenta de la administración del Monte cada cuatro meses. El Padre Depositario estaba obligado a estar al corriente siempre del precio del centeno, información que debía comunicar al Padre Presidente que, junto con los Padres Contadores, decidía y aprobaba el precio al que se vendería el centeno del Monte. Las cantidades obtenidas de estas ventas debían ser ingresadas por el depositario en el arca de la comunidad, en presencia del Padre Presidente y de los contadores, quienes también debían estar presentes para poder sacar cualquier cantidad. El caudal del Monte debía estar separado del resto de dinero del Monasterio.

El padre depositario custodiaba la llave del cajón donde se guardaba el dinero del Monte y tenía asignada una celda, con puerta y llave, donde depositar el centeno. En la recepción del grano, que se renovaba anualmente, debía estar presente el padre Presidente.

Se establecía en los estatutos además, que el excedente de los 2.000 ducados que se había fijado como capital base del Monte, se debía emplear en comprar hacienda raíz a imposición de censos o en lo que dispusiera toda la comunidad. Por último, los padres Presidentes solo podían valerse del dinero del Monte en los únicos casos en que no hubiera otro recurso.

Por tanto, vemos como este Monte se funda para convertirse en un depósito que asegure y acreciente las rentas del Monasterio, disponiendo así la comunidad de un caudal para las ocasiones en que se requería un desembolso elevado. El caso de las obras en el Monasterio se pone como ejemplo en el acta fundacional que estamos estudiando.

Las anotaciones que se conservan de esta fundación nos ofrecen, en su mayoría, la toma de razón realizada anualmente. Solo se observan estos tres grupos de gastos extraordinarios en el período 1745-1835:

- 2 de febrero de 1793: se obtiene dispensa del General de la Orden para sacar del fondo del Monte la cantidad de 300 ducados para emplearlos en socorros y dotes de labradores y huérfanas pobres ${ }^{4}$. La comunidad decide que se do-

\footnotetext{
${ }^{3}$ AHN, Clero, L. 9919..., fol. 1r.

${ }^{4}$ La solicitud para conseguir el permiso para sacar esta cantidad incluye los motivos: «...para el cumplimiento de las reales y piadosas intenciones del Rey nuestro señor y de sus Ministros que con el

Hispania Sacra, LXI

124, julio-diciembre 2009, 571-586, ISSN: 0018-215-X
} 
ten 3 huérfanas con 50 ducados cada una y los restantes 150 ducados se repartan entre los labradores necesitados.

- 2 de mayo de $1793^{5}$ manda el General de la Orden contribuir con cierta cantidad «al bien de la Patria y a quanto puede ser del Real Servicio del Rey Nuestro Señor (que Dios guarde)... considerando las urgencias en que se halla al presente empeñada la Corona y el honor de toda la nación española...» ${ }^{6}$. Se establece que el Monasterio contribuya con 734 reales de vellón por cada religioso que formase la comunidad, en total 14.680 reales de vellón. De esta cantidad, finalmente, se aporta del caudal del Monte 14.311 reales de vellón, el resto se completa de los fondos del Monasterio. Un gasto similar se produce el 11 de junio de 1808 , cuando se sacan 8.850 reales de vellón para socorro de las tropas españolas que salían del reino de Galicia contra los franceses ${ }^{7}$. El 1 de octubre de 1814 el Rey vuelve a pedir aportaciones monetarias.

- Por último, se aprueban varios gastos para llevar a cabo diferentes obras en el Monasterio. Son en total cinco anotaciones entre 1811 y $1835^{8}$.

Se trata, por tanto, de un Monte fundado para conseguir reunir un depósito suficiente y capaz de servir al monasterio en épocas de dificultades económicas, en realidad, para imprevistos, casi siempre relacionados con las obras para mantener el monasterio. El recurso principal del depósito es el grano, cuyo precio de venta se determinará en cada ocasión. No estamos ante un Monte con fines públicos sino privados, aunque, en ocasiones, su caudal se utilizara para colaborar con fines públicos.

\footnotetext{
motivo de los prosperos sucesores que la Divina Misericordia se ha dignado dispensar a Nuestra Monarquia, concediendo los singulares beneficios del importante y ventajoso de la paz y el de la augusta fecunda sucesion de los dos Serenisimos infantes y la Princesa Nuestra Señora dio a luz en su felicísimo y dichoso parto, desean facilitar a los vasallos los medios mas oportunos de aliviarles y para llebarlos a debida execucion ordenan que todos los Superiores Regulares asignen por una vez las cantidades que les dicte su caridad y posibilidad religiosa, convirtiendolas en Dotes de Huerfanas y socorro de labradores, debiendo executar lo mismo de las Obras Pias que estén puestas a su direccion». AHN, Clero, L. 9919..., fol. 10r.

${ }^{5}$ En 1793, con motivo de la guerra con Francia, se esperaba que la Iglesia contribuyera de forma generosa a la Hacienda real, produciéndose una oleada de contribuciones del clero (William J. CALLAHAM, Iglesia, poder y sociedad en España, 1750-1847. Nerea, Madrid, 1989, p.81.)

${ }^{6}$ AHN, Clero, L. 9919..., fol. 14r.

${ }^{7}$ Ibidem, fol. 21r.

${ }^{8}$ Ibidem, fol. 23 y ss.
} 


\section{Monte de Piedad del Monasterio de Santa María de Monfero, La Coruña ${ }^{9}$}

Vinculado también a un monasterio de la orden de San Bernardo y situado en Galicia, faltan en las fuentes documentales datos contables de relevancia. Solo tenemos su acta fundacional. Vamos a ver las similitudes con el anterior.

Los fines de esta fundación son los mismos que el caso de Pontevedra. La comunidad se reúne «...para conferir sobre gobierno temporal del Monasterio y para que sus rentas dedicadas por los piadosos fundadores y bienhechores al sustento de los monjes que en el sirven no se menoscaben antes bien se conserven y aumenten despues de varios medios que para este fin fueren propuestos eligieron unanimes una especie de deposito o Monte de Piedad...»10.

Se establece que el Abad debía depositar 35 fanegas de centeno hasta lograr reunir 30.000 reales de vellón, conservando siempre en metálico o en grano la mencionada cantidad de reales de vellón. Este capital tiene como fin «...subvenir a los Padres Abades en aquellos casos en que necesitados notoriamente de dinero para la manutencion de esta comunidad y precisados por esto a vender los frutos a precios infimos no los vendan y se revalgan del dinero de este particular deposito en la forma y modo que abajo se expresara» ${ }^{11}$. El texto es idéntico al de Acebeiro.

La comunidad elegiría al depositario entre los monjes, al mes de firmada y aprobada la escritura de fundación. Los contadores debían ser dos de los monjes más graduados, siendo uno de ellos el Padre Prior. Darían al Abad razón de la administración cada cuatro meses. El depositario debe estar también informado del precio del centeno para poder comunicarlo al Abad, contadores y monjes más ancianos antes de determinar el precio al que debía venderse el grano.

En cuanto al carca, ingresos y extracción de caudal del Monte, lugar donde almacenar el grano, custodios de las llaves, renovación del grano y el destino del exceso de los 30.000 reales de vellón con que el depósito siempre debe contar, esta fundación coincide exactamente con la de Pontevedra.

Las similitudes de ambas fundaciones son claras, lo que nos lleva a pensar que pudieron surgir a propuesta de la Orden como remedio a las dificultades económicas por las que podían estar pasando ambos monasterios. Queda sin despejar la incógnita de si éstos fueron los únicos monasterios con Montes de Piedad o depósitos de este tipo.

\footnotetext{
${ }^{9}$ AHN, Clero, L. 3084. Libro del Monte de Piedad, 1745-1834, del Monasterio de Santa María de Monfero. La Coruña.

${ }^{10}$ Ibidem.

11 Ibidem.
} 
Montes de Piedad PRIVAdos Fundados POR PARTICUlaRes

Los dos ejemplos que estudiaremos en este apartado difieren bastante entre sí. Ambos fundados por particulares pero con objetivos bien diferenciados. El primero de ellos se asemeja más a una memoria testamentaria mientras que el segundo se acerca más a la tipología de los Montes frumentarios. Coinciden además en que la noticia de su existencia nos llega por la documentación que generaron sendos pleitos, si bien, lo que nos interesa aquí es el análisis de las fundaciones y no tanto las cuestiones judiciales.

\section{Monte de Piedad fundado por José Francisco Álvarez. Salamanca, 173712}

La escritura de fundación de este Monte está fechada en 1737. José Francisco Álvarez, regidor que fue de Salamanca, la otorga en virtud del poder que le había concedido la difunta María Ana de Rueda Maldonado, su mujer. Ésta, por medio de su testamento (1730) disponía en una de sus cláusulas que con un quinto de los bienes que dejaba se instituyera esta fundación en el Hospital General de la Santísima Trinidad de Salamanca, en cuya iglesia estaba enterrada.

El Monte estaba nacía para a socorrer a los parientes del matrimonio, dejando a su marido la decisión y responsabilidad del establecimiento de las ordenanzas que debían regirlo y los detalles de los familiares que podían beneficiarse de esta memoria. Hecho inventario de los bienes testamentarios, se estima que el quinto con que debía fundarse el Monte eran 160.000 reales de vellón. No obstante, esta cantidad queda reducida a 110.000 reales de vellón, pues se decide reservar 50.000 reales de vellón para los gastos del funeral. Esta cantidad se hace efectiva una parte en trigo (5.628 reales de vellón) y otra parte en metálico (8.696 reales de vellón).

José Francisco Álvarez añade posteriormente, un quinto de sus propios bienes para incrementar el capital del Monte y establece que la fundación debe beneficiar a sus hijos y sus descendientes y a los pobres del Hospital. Las ordenanzas establecidas por el fundador y que regirán el Monte son:

- Las rentas deben servir y convertirse en dar dotaciones a los descendientes de José y Antonio Manuel Álvarez, los dos hijos del matrimonio fundador, y a Josefa y Francisco de Rueda, sobrinos del mismo. Desaparecidas estas cuatro líneas, vinculadas a mayorazgo, las rentas servirán para ayudar a la fundación y mantenimiento del Hospital de Convalecencia, incluido en las fundaciones de dichos mayorazgos con la carga de dos misas cantadas perpetuas.

12 Archivo de la Real Chancillería de Valladolid, Alonso Rodríguez, 2527, Exp. 1; Ibidem, Pérez Alonso, 2710, Exp. 3. 
- A las hijas y demás mujeres descendientes de los hijos y sobrinos mencionados se les ha de dar para ayuda de su remedio de casadas o religiosas ejecutando antes de cumplir 25 años, 9.000 reales de vellón a cada una por una vez, sin que sea necesario para la verificación más que la fe de profesión o velaciones. Pasados los 25 años, si quedaran solteras, también se les dará la misma cantidad. Si no hubiera capital y acudieran varias parientas a cobrar, debe preferirse a la más cercana, $y$, siendo de igual grado, a la que sea más pobre.

- Deben sacarse de las rentas de esta fundación 1.000 reales para el Hospital General y ayuda de curar a los pobres enfermos. De estos 1.000 reales el Hospital está obligado a que en su iglesia en los días de San José y Santa Ana o en su octava se digan dos misas cantadas con asistencia de toda la diputación y Patronos de Sangre, cantadas con Diacono y Subdiácono y ofrecidas por el alma de los fundadores, María Ana de Rueda y José Francisco Álvarez, y de todos sus demás parientes difuntos.

- Deben gozar de esta dotación los varones descendientes de José y Antonio Álvarez y Josefa y Francisco de Rueda. Los varones descendientes de los dos primeros, con 5.400 reales de vellón por una vez a los 25 años, habiendo dos, preferir al más cercano o al más pobre. Al dar esta dotación se sacaran 600 reales para decir una misa cantada en la iglesia del Santo Hospital.

- En un mismo año no podrá darse más que dos dotaciones. Si hubiera más peticiones, podrían darse, en caso de que en años anteriores no se hubieran dado, «prefiriendo a las mujeres o varones de mis hijos antes que a los de mis sobrinos». Para pagar las dotaciones no se harán autos judiciales ni informaciones de testigos.

- Las mujeres o varones que posean los mayorazgos que gocen sus hijos no recibirán las expresadas dotaciones.

- José Francisco Álvarez será el patrono del Monte mientras viva. Después le sucederán sus hijos y a éstos, sus descendientes. Serán patronos aquellos descendientes que gocen del mayorazgo familiar. Si éstas son mujeres, los patronos serán sus maridos y si fueran religiosas, podrán dar poderes. Sus sucesores en el patronato del Monte deberán nombrar un administrador que cuide de las propiedades y rentas y del estado del trigo, el cual no podrá vender sin licencia por escrito de los patronos. El administrador debe dar cuentas cada dos años. Además se nombrarán dos diputados, uno eclesiástico y otro secular pertenecientes a la diputación del Hospital General y elegidos por la misma diputación.

Una vez que los hijos de los fundadores se he hacen cargo del Monte, se inicia el pleito entre el Hospital y los herederos, en el que el primero reclama la puesta en marcha de la fundación y los segundos piden que se declare sin valor la fundación. 
Este tipo de Monte se nos presenta como un caso bastante opuesto a los fines de las instituciones originarias. Estamos ante una memoria testamentaría, una obra pía dirigida a dotar a descendientes de una línea de la familia concreta cuya vinculación al mayorazgo familiar determina el acceso a los fondos del Monte. Es un Monte con fines privados.

Monte de Piedad fundado por Juana de los Ríos. Villa de Navarrete, La Rioja. $[1746]^{13}$

La noticia de la fundación de este Monte de Piedad nos llega también a través de un pleito. Juan Bautista de la Barra y Zúñiga, patrono del Monte de Piedad, fundado por su tía Juana de los Ríos y Angulo, viuda de Pedro de Medrano, caballero de Santiago, Consejero de S.M., y Secretario de Estado de Italia, se defiende de las acusaciones de Diego de Coca, vecino de Navarrete y lugar donde se instituye el Monte, en relación a los muchos atrasos con que se encontraba la obra pía. Los autos tienen lugar en 1746.

Juana de los Ríos deja diferentes caudales para la fundación de un Monte de Piedad. Establece una renta anual perpetua de 400 ducados, debiéndose llegar a las 3.000 fanegas de trigo las cuales debían ponerse en el Arca de Misericordia para el alivio y sustento de los vecinos y moradores de la villa de Navarrete. Debía repartirse el trigo en tiempo de la sementera para cubrir cada uno sus tierras y para el socorro y urgentes necesidades que se padecen en lo riguroso del invierno, siendo la obligación de los vecinos reintegrar el trigo.

Parece que este Monte nunca llegó a alcanzar las cantidades de grano que había dispuesto su fundadora, pues sólo se llegó a reunir 2.000 fanegas de trigo. Esto se une a que los vecinos que fueron recibiendo el trigo nunca devolvieron cantidad alguna, como certifica Mateo Serrano, notario de las obras pías de Juana de los Ríos, tras revisar las cuentas del Monte entre los años de 1720 y 1728. En 1740 los patronos del Monte desisten de reclamar a los vecinos que deben trigo al Monte por serles imposible su devolución.

Este Monte es ejemplo de las muchas fundaciones que se crearon, especialmente, en ámbito rural, en el que las personas más o menos acaudaladas del lugar, en vez de fundar las típicas obras pías y memorias testamentarias o además de ellas, dejaban parte de sus bienes para la erección de obras para beneficio público. Confiando en que su gestión y actividad lograrían con los años convertir sus obras en establecimientos tradicionales. Los fundadores no contaban con la posible desatención de los administradores, por regla general descendientes

\footnotetext{
${ }^{13}$ AHN, Consejos, Leg. 27046, Exp. 4.
} 
suyos, que buscarían beneficiarse ellos mismos. Tampoco tenían en cuenta que el capital que dejaban terminaba siendo insuficiente y la obra, si llegaba a ponerse en marcha, no superaba unos pocos años de vida.

\section{Montes De PiedAd PRIVAdOS FUNDADOS POR NOBLES}

Por último, incluimos dos ejemplos de dos nuevos Montes de Piedad, cuyos fundadores pertenecen a la nobleza, y que tienen muchas similitudes con el Monte de Piedad de Madrid.

Era habitual que personas acaudaladas dotaran de este tipo de instituciones a las comunidades rurales con las que tenían vínculos, este es el caso del Monte de Piedad de Frigiliana y el de Béjar. Por eso una de las características principales de todos ellos es que el depósito inicial fuera en grano y, en menor medida, en dinero.

\section{Monte de Piedad de Béjar, $1720^{14}$}

Es uno de los herederos directos del fundado por el padre Piquer en Madrid a principios de la centuria. Utilizaron sus estatutos para redactar los propios, adaptados al lugar de la fundación y a las necesidades de su población, siendo la diferencia más evidente que los préstamos se harán principalmente en grano. Entre sus objetivos, además de los préstamos a necesitados, el alivio de las penas de las ánimas.

Los patronos son Juan Manuel Diego López de Zúñiga, Segundo Duque de Béjar y el Obispo de Plasencia Francisco de Perea y Porras. Ambos realizan la aportación económica necesaria para la fundación El Obispo Perea aporta 12 fanegas de centeno y el Duque de Béjar la renta que produzca una panera, 48 fanegas de centeno y 12 fanegas de trigo y otras 12 de centeno. El Duque «escribio a los concejos enterrandolos de esta fundazion para su utilidad y para animarlos si tenian devocion de ayudar con alguna limosna de granos, vino o dinero para ayuda del fondo de esta piadosa obra»15.

La escritura de fundación, otorgada el 20 de agosto de $1720^{16}$, queda instituida de la siguiente manera:

- El Monte queda erigido para sufragio de las Benditas Ánimas del Purgatorio y para el socorro común de los necesitados. Bajo la protección del Obispo

\footnotetext{
${ }^{14}$ AHN, Sección de Nobleza, Osuna, C. 258, D. 56. Monte de Piedad para alivio de las Ánimas y socorro de los necesitados en la villa de Béjar.

15 Ibidem, fol. 2.

${ }^{16}$ Ibidem, fol. 62.
} 
de Plasencia y del Duque de Béjar. Se erige en la Parroquia de Santa María y en ella tendrán lugar las celebraciones de aniversarios y misas hasta que el volumen de las limosnas permita repartir a otros templos.

- Cuenta con una Junta General y una Junta Particular. La primera formada por el Padre Guardián del Convento de San Francisco de Béjar, el Vicario eclesiástico, el Corregidor y el Contador Mayor de la Casa de Béjar. Su misión será resolver los problemas y dudas que pueda elevar la Junta Particular. Los protectores tendrán voto de calidad y se reunirá cada año, 1 de mayo y 1 de Noviembre. La Junta Particular se compone de cuatro interventores, dos eclesiásticos, nombrados por el Obispo, y dos seculares, nombrados por el Duque. Habrá también un secretario-contador, un tesorero, un depositario y un portero.

- Los préstamos se efectuarán sobre alhajas, con la aprobación de la Junta General, en dinero o en grano, no concediendo préstamos superiores a 100 reales o a una carga de grano, al menos al principio.

- En lo espiritual se establece la recogida de limosnas y el sufragio de misas "que se a de solicitar con el maior celo y devozion recojer limosnas en esta villa y su tierra y se han de poner cajas en los lugares públicos, casas de comercio y particulares de devotos y de ellas se a de hazer y decir las Misas correspondientes a las limosnas que ubiere juntas y si en adelante ubiere caudal para un Novenario con oficio y Misa cantada y repartir limosna de Misas se hara con la consulta y determinazion de la Junta General»17.

En 1721 fallece Pedro de Zúñiga, Duque de Nájera y hermano del de Béjar, éste se retira a Madrid. Su ausencia de Béjar conlleva la falta de su apoyo al Monte quedando desasistida la obra. En 1732 se vende todo el grano del Monte convirtiendo su importe, por orden del Duque, en misas por las ánimas del Purgatorio.

\section{Monte de Piedad de Frigiliana, 1717}

Se funda a iniciativa de Margarita de Tabora, Condesa de Frigiliana. Tenemos noticia de él a partir de una donación de su nieto a favor de la fundación ${ }^{18}$. Margarita de Tabora aporta el capital inicial del Monte, en forma de 60 fanegas de trigo, pues estamos ante un Monte Frumentario. El documento que nos aporta toda esta información, además de constatar una donación sirve de revisión

17 Ibidem, fols. 64 y 65.

18 AHN, Sección de Nobleza, Fernanúñez, C. 1017, D. 5. Donación hecha por el conde de Aguilar y Frigiliana, Señor de los Cameros, en favor de la villa de Frigiliana de la cárcel y granero para los granos del Monte de Piedad. 1717. 
tanto de la fundación como de su normativa aprovechando el Conde de Frigiliana ${ }^{19}$ para introducir algunas novedades.

La villa de Frigiliana pone en conocimiento del Conde que no existe lugar donde guardar y recoger el grano perteneciente al Monte. La noticia motiva la donación: «(...) y por quanto yo tengo un sitio labrado, enmaderado, cuvierto de teja, con su alto y vajo, puertas y ventanas, que hasta oy ha servido y sirve de carcel, y el alto de recoger dichos granos de dicha obra pia, de que soy patrono como quien dio de su acienda propia el capital p(ar)a su institucion, y dicho sitio esta en la calle que llaman de Granada (...) por la presente ottorgo que hago grazia y donazion pura, perfecta acabada (...) para que esta villa, justicia y regimiento husen de ella a su voluntad, (...) con la obligacion de tenerla bien reparada con sus puertas y ventanas y maior seguridad (...)» ${ }^{20}$.

Aunque la donación es inmediata, el Conde solicita informaciones para poner en orden la fundación ${ }^{21}$. En ellas se detecta que está haciéndose un uso indebido del Monte, ya que en la villa se le consideraba un pósito llegando a denominarlo de esta forma.

Las bases fundacionales y ordenanzas y el control sobre los pósitos, nada tenían que ver con la obra pía que había pretendido dar inicio Margarita de Tabora con su inicial donación de 60 fanegas de trigo. Cedidas en un principio para aliviar las necesidades de los labradores, la devolución de este préstamo inicial, incrementado con las creces, debía conformar el Monte de Piedad que, a partir de entonces continuara con su actividad benéfica de facilitar grano en época de carestía, para siembra y para alimento.

El conde de Frigiliana solicitaba la certificación de las cuentas del Monte, y al mismo tiempo, ordenaba a la justicia de la villa que se realizara información entre

\footnotetext{
19 Iñigo de la Cruz Manrique de Lara Ramírez de Arellano Mendoza y Alvarado, tercer Conde de Frigiliana.

${ }^{20}$ AHN, Sección de Nobleza, Fernanúñez, C. 1017, D. 5. Donación hecha por el conde de Aguilar y Frigiliana, ...

21 «...) poner al corriente el prestamo que mi abuela, doña Margarita de Tabora, condesa de Frigiliana, de sesenta fanegas de trigo que repartidas en las necesidades de la villa con la institucion de las creces de un almud, fuere un Monte de Piedad, que asi aumentado fuese del alivio mayor del publico, como establecer en los benidero reglas con que no so se ebiten los yncombeniente que en las que hasta aora ha havido en este caudal. Se han reconocido y assi mismo que con el nombre equiboco que hasta oy ha tenido de posito, no se sigan los yncombenientes y generalmente ya en el repartido ya en el cobrado, ya en la quenta de el reconozen como todos los que tienen este titulo y no siendo este pues para su fundacion hubo mas facultad que esta benebolencia de mi abuela ni otro de los requisitos que para la fundacion de tal posito se requieren». AHN, Sección de Nobleza, Fernanúñez, C. 1053, D. 30. Mayorazgo del Señor Don Luis Pacheco Arroniz. Monte de Piedad que fundó la Señora Doña Margarita de Tabora. Autos hechos en virtud de Decreto del Exmo. Sr. Conde de Aguilar, Señor de los Cameros, sobre la justificación de la obra pía, el Monte de Piedad que en esta villa fundó la Ilma. Sra. Doña Margarita de Tabora, condesa de Frigiliana. 1717.
}

Hispania Sacra, LXI

124, julio-diciembre 2009, 571-586, ISSN: 0018-215-X 
los vecinos para que quedase claro que la fundación era benéfica y, por tanto, no era un pósito. El decreto originado incluía novedades en las ordenanzas ${ }^{22}$ :

«Lo primero, que el quarto donde estubiese el dicho Monte de Piedad, tenga tres llabes diferentes, que la una la tenga el gobernador, la segunda el personero o procurador general y la terzera el administrador del Monte de Piedad, y en defecto de qualquiera de estos, deposite la justicia en uno de los regidores. Nunca se ha de abrir sin concurrencia de los tres.

La segunda, que dentro del mismo Monte haya un libro de quenta y razon en el que se escriva el dia y ora en que se habre y zierra dicho Monte de Piedad para cuio fin y los que se distribuyere llebando en el, el cargo y data del caudal con quenta y razon, el que ha de ser satisfacion de la residencia, de si los que han tenido esto a su cuidado han cumplido con su obligacion» 23 .

Se pone en práctica con la primera norma la habitual en las instituciones con una arca donde depositar los caudales, las «arcas de tres llaves», típicas de los Montes de Piedad y en concreto del de Madrid. De igual forma, la existencia de esta arca, implicaba la de los libros de cuenta y razón destinados a llevar la contabilidad de la institución, exigiéndose que se registraran todos los movimientos. En este caso, a diferencia del Monte de Piedad de Madrid, no se abrían arcas, sino el Monte en sí, que el depósito del grano.

«Lo terzero que quando se saque qualquier partida, que nunca se pueda dar ninguna si no a vezino segun la disposicion de la fundadora, ha de hazer obligazion ante el ayuntamiento en fabor de dicho Monte de Piedad de restituir la cantidad que percibiere y un quartillo o mas cada fanega para el dia de Nuestra Señora de Agosto el qual pasado se les ha de apremiar por todo rigor de derecho y bia efectiva a la restitucion de dicho capital y reditos respecto de haver reconocido los reditos de un almud antes que adelantan el dicho Monte de Piedad y porque este por su propio titulo dize no debe seguir las reglas del posito» 24 .

Al igual que en los otros Montes, se requiere una garantía. En este caso no se trata de garantías prendarias sino de una obligación ante la autoridad de la vi$1 a^{25}$, comprometiéndose a la devolución del grano obtenido junto con una parte más. También se fija el plazo en el que debe ser devuelto el «préstamo».

«Lo quarto, que para la distribucion de todo o parte de dicho Monte de Piedad, nunca se haya de poder hazer sin que se junte la villa y los tres que como se refiere han de

\footnotetext{
22 Ibidem. Decreto de 8 de julio de 1717.

23 Ibidem.

24 Ibidem.

25 En el caso del Monte de Piedad de Madrid, también hubo prestatarios que en lugar de dejar una prenda empeñada, dejaban un documento por el que se obligaban a la devolución del préstamo obtenido, fijando en el mismo, cláusulas de penalización si no se llevaba a cabo.
} 
tener las llabes y quatro hombres de los más probectos y juiziosos del pueblo en cuia junta a pluralidad de botos se ha de resolber lo que en esto se haya de ejecutar, dandome ynmediatamente a mi o a mis subcesores quenta de ello.

Lo quinto, que de ellos tres que han de tener las llabes, el que no tienen oficio en el ayuntamiento y si es el administrador se mejore porque en las elecziones para que benga nombrado en el titulo.

Lo sexto, que estos tales han de tener estas llabes al entregarselas, se le ha de rezivir por la villa fianza de hasta mill ducados entre los tres. Lo qual ha de correr por quenta la villa que se ha de entregar ante el escrivano de ayuntamiento de ella y para que desde aora se empieze la cobranza nombro desde luego a Andres de Arrabal por personero y procurador general de esta mi villa de Frigiliana y a Francisco Rodriguez por administrador de dicho Monte de Piedad, los quales reyntegren y perziban al dicho Monte de Piedad las cantidades y de las personas abajo ynsertas en el termino de tres años cuia primera paga ha de ser por el dia de Nuestra Señora de Agosto de 717 adelantando quanto puedan esta cobranza en dichos 3 años para que este dicho Monte de Piedad este enteramente restablecido quanto antes» ${ }^{26}$.

Las últimas indicaciones, se refieren a las diferentes medidas a tomar para que la fundación garantice los préstamos y las devoluciones. Los encargados de realizar los préstamos deben asegurar la buena administración y el correcto desempeño de sus cargos.

Este Monte Frumentario es, por tanto, otro ejemplo de los tipos de Montes que se crearon. En la Edad Moderna proliferaron las instituciones con este nombre aunque no siempre se ajustaban a las características originales establecidas en Italia, muchas obras pías tenían más que ver con otras instituciones que recibieron el nombre de Montes de Piedad. En este caso, una institución benéfica fundada a partir de una donación inicial realizada por la condesa de Frigiliana debía acrecentarse con la participación de los propios prestatarios.

Don Rodrigo Manrique de Lara, cuya intervención en el Monte de Piedad de Madrid fue muy importante, no desconocía estas instituciones pues su madre había llevado a cabo una fundación similar.

\section{CONCLUSIONES}

Los fines de este tipo de fundaciones, que los predicadores franciscanos en el siglo XV en Italia denominaron Montes de Piedad, eran bien distintos del que hemos visto en los Montes aquí descritos.

En su origen el fin principal era instituir un medio para luchar contra la usura, ofreciendo préstamos a un bajo interés, todo dirigido a aliviar la situación económica de los necesitados. Su fin era el bien público. Trasladado ese mode-

\footnotetext{
${ }^{26}$ SN-AHN, Fernanúñez, C. 1053, D. 30...
}

Hispania Sacra, LXI

124, julio-diciembre 2009, 571-586, ISSN: 0018-215-X 
lo a Madrid ya en el siglo XVIII, los objetivos quedan perfectamente definidos por el Padre Piquer: el socorro económico de los necesitados por medio de préstamos sin interés y el alivio de las penas de las ánimas del Purgatorio por medio de sufragios.

El Monte madrileño, a diferencia de los italianos, descarta el cobrar intereses, por bajos que fueran, por los préstamos repartidos. El carácter devoto de su fundador dejaba a iniciativa de los prestatarios la posibilidad de hacer alguna limosna en el momento de la devolución del préstamo, limosnas dedicadas a sufragios por las ánimas. Piquer también les dejaba que decidieran si las misas que se sufragarían con su limosna eran por las ánimas en general o por la de algún difunto en particular. Establecía además que el capital del Monte debía formarse con los depósitos de aquellos que quisieran cederle una cantidad de dinero para préstamos. Los depositantes tampoco recibían intereses que incrementasen el capital depositado. Eran depósitos caritativos. A ojos del Padre Piquer, todas estas acciones unidas daban forma, literalmente, a un Monte de Piedad, acciones que se convertían en un tesoro espiritual que beneficiaba a vivos y difuntos. Paralelamente, se desarrolló el capital de las ánimas por medio de las limosnas recogidas por otros medios ${ }^{27}$.

Muy diferente es el caso de los Montes creados en Galicia en ambos monasterios de la Orden de San Bernardo. El objetivo aquí era formar un fondo que les sirviera de remante y que pudiera utilizarse en momentos de dificultad económica para la comunidad. Y aunque, podríamos reconocerles una función similar a los Montes frumentarios o los pósitos, en realidad el fin principal era indiscutiblemente privado, aunque sus fondos se utilizaran, excepcionalmente, a instancias del monarca para alivio de la Hacienda real. Así con motivo de diferentes enfrentamientos bélicos y en una situación que entre 1790 y 1808 la Iglesia sufrió la erosión de sus recursos financieros, se solicitó su contribución económica ${ }^{28}$. En 1798 y en un estado de guerra con Inglaterra, el Estado buscó la ayuda de la Iglesia. El cabildo de Santiago, a pesar de las dificultades económicas, logró reunir 500.000 reales para la defensa de la región contra un ataque inglés ${ }^{29}$. En esta coyuntura, agravada posteriormente con la intervención de las fuerzas napoleónicas, se enmarcan las diferentes contribuciones procedentes de los Montes de Piedad aquí estudiados.

${ }_{27} \mathrm{M}^{\mathrm{a}}$ Teresa Muñoz Serrulla, Francisco Piquer y la creación del Monte de Piedad de Madrid (1702-1739): Moneda, Espiritualidad y su Proyección en Indias. Universidad Complutense de Madrid, Madrid, 2005. (Edición Digital).

28 William J. Callaham, Iglesia, poder...p.78.

${ }^{29}$ Ibidem, p. 81. Igualmente en 1795 la Hacienda Real tenía tan pocos recursos que el rey ordenó que los cabildos catedralicios de toda España enviasen a las casas de la moneda de Sevilla y Madrid los ornamentos de oro y palta que no se usaran en los servicios litúrgicos. 
Respecto a estos fines privados, igual ocurre con la fundación de Salamanca, en la que las características de una capellanía o legado testamentario son claras. Los fines son igualmente particulares e incluso limitados a los miembros de la familia. Quizá podríamos encontrar algún parecido con los Montes fundados en Italia, destinados a dotar jóvenes para tomar estado, como el del Monte de la Dote florentino, que funcionó entre 1425 y 1577 , dedicado a recibir depósitos recuperables en el momento del matrimonio, si bien esta institución estaba dirigida a familias con una buena situación económica. El Monte del Matrimonio de Bolonia, fundado en 1583, estaba dirigido en este caso a familias con pocos recursos económicos ${ }^{30}$. Sin embargo, el carácter público no se refleja en la fundación salmantina.

Distintas son las tres fundaciones restantes. Son Montes fundados por personas influyentes y con una buena posición económica. Dos de ellos son iniciativa de nobles y el tercero se crea a instancias de Juana de los Ríos, viuda de Pedro Medrano, caballero de Santiago, Consejero y Secretario del rey. En estos casos, el objetivo es dotar a las poblaciones correspondientes, de una fundación que asegure el préstamo de grano en época de malas cosechas. El fin público queda claro en estos casos, al tiempo que se mezclan elementos piadosos, heredados de la fundación de Piquer, como en el Monte de Béjar, que incluía el sufragio por las ánimas del Purgatorio en sus fines.

Comunes en los Montes descritos son su corta duración, salvo los eclesiásticos, y los pleitos que en los particulares originaron los herederos de los fundadores.

Por tanto, es evidente, aunque el análisis es sobre un número reducido de casos, que los Montes de Piedad en España, evolucionaron desde la fundación del Monte madrileño, en primer lugar hacia instituciones o fundaciones diferentes de la originaria, tanto desde el punto de vista de Madrid como desde Italia. Mantuvieron la denominación, aunque estas fundaciones nada o poco tenían que ver con los fines característicos. Derivaron a fundaciones que no lograron afianzarse y, al poco tiempo de iniciar su actividad, fueron desatendidos sus fines o los herederos de sus fundadores, disconformes con ellos, entablaron pleitos judiciales relacionados sobre con asuntos económicos. Por último, destacar esa adaptación de los Montes a fines particulares de los fundadores, los cuales siempre contemplaron un fin público secundario que justificaba su erección.

\footnotetext{
30 Mauro CARBoni, Le doti della povertà. Famiglia, risparmio, previdenza: il Monte del Matrimonio di Bologna (1583-1796). Il Mulino-Fondazione del Monte di Bologna e Ravenna. Bologna, 1999, pp. 13-16. Resalta el autor en este estudio la importancia de la dote para la familia de la mujer, presentando la asignación dotal como clave para las aspiraciones sociales de la familia de la mujer.
}

Hispania Sacra, LXI

124, julio-diciembre 2009, 571-586, ISSN: 0018-215-X 